\title{
Utilização de vídeo-aulas como estratégia auxiliar de ensino numa turma de EDO
}

\author{
Mateus Bernardes, \\ Depto Acadêmico de Matemática, UTFPR \\ 80230-901, Curitiba, PR \\ E-mail: mbernardes@utfpr.edu.br.
}

\begin{abstract}
Resumo: Este trabalho relata a experiência do uso de vídeo-aulas de curta/média duração numa turma regular de EDO oferecida a alunos do terceiro semestre de engenharia na UTFPR. Apoiado no tripé Motivação/Independência/Flexibilidade mostra-se que esta estratégia pode ser um recurso auxiliar ao processo de aprendizagem do aluno e, caso bem aproveitado permite até uma reformulação da dinâmica adotada em sala de aula.
\end{abstract}

Palavras-chave: Estratégias de ensino, Recursos audiovisuais, Matemática Aplicada

\section{Exposição do Problema}

Os estudantes da era digital não percorrem os mesmos caminhos de aprendizagem que nós professores percorríamos há poucos anos atrás. Enquanto o livre acesso à informação é uma das virtudes desta época, o excesso de informação e a dificuldade em filtrá-las talvez seja seu maior defeito.

Muitos dos futuros engenheiro ou licenciado em Ciências Exatas apresentam inúmeras dificuldades no acompanhamento de seus cursos de graduação. Algumas delas, mas nem todas, são decorrentes de falhas de formação em nível fundamental e médio. Falta de motivação por parte dos alunos; dificuldade de comunicação entre professor e aluno; e, principalmente, a complexidade de assuntos como cálculo, álgebra linear e física superior para citar o mínimo, também podem ser incluídos nesta lista.

Curiosamente alguns aspectos diagnosticados como problemáticos neste início de século XXI já eram relatados muitos anos antes, como nos conta [1]:

"No verão de 1976, eu, Carlos, Celso e Paulo reunimo-nos, no apartamento do Celso, em Ipanema, para discutir uma proposta de criação de um curso alternativo para os alunos que, embora classificando-se para ingressar na universidade, não obtivessem média 7.0 (no mínimo) nas disciplinas de Matemática, no vestibular. Na época, éramos todos professores da PUC/RJ e a universidade preocupava-se com o decrescimento, ano após ano, do nível de conhecimento e formação dos novos alunos, que eram reprovados em massa nas disciplinas de Cálculo I e Física I".

A queixa persiste e reaparece, agora em 1997, como cita [4]:

"É procedente informar ao leitor que alguns estudantes matriculados nos cursos de Cálculo não sabem somar frações !!!".

E que não fique a impressão de que trata-se de uma questão isolada, regionalmente específica do ensino de Matemática no Brasil. O relato também se encaixa em outros centros, inclusive 
tidos com mais desenvolvidos, com relata [3], professor em Stanford:

"Many students encounter difficulty going from high school math to college-level mathematics. [...] Though the majority survive the transition, many do not, and leave mathematics for some major (possibly outside the sciences or other mathematically-dependent subjects). To help incoming students make the shift, college and universities often have a "transition course".

O público que assiste a um curso de EDO (ou Cálculo III em algumas instituições) é um tanto diferente daquele que inicia a vida universitária pelos cursos de Cálculo. Neste curso os alunos (em tese) já cursaram Cálculo de uma e de várias variáveis além de Álgebra Linear, portanto são alunos cuja bagagem matemática é maior e de quem se espera um pouco mais de maturidade por se tratar de um aluno de terceiro semestre (no mínimo). Mesmo assim o que se nota em sala de aula não chega a ser muito animador. Com frquência os alunos encontram-se desmotivados, à beira da sonolência ou dispersos às custas da disponibilidade de rede aberta wifi por todo o câmpus. Isso ajuda a gerar uma atitude passiva diante do aprendizado: o professor fala (e/ou escreve), eu anoto. Missão cumprida.

\section{Metodologia}

Partiu-se então para a ideia de disponibilizar uma ferramenta de auxílio ao processo de ensinoaprendizagem de EDO: vídeo-aulas de curta/média duração. Sem abrir mão das mídias tradicionais (giz, lousa, voz), a inclusão de uma nova mídia pretende contribuir para o referido processo exatamente onde as ferramentas tradicionais muitas vezes apresentam as maiores dificuldades:

- Motivação: O formato de vídeos educacionais de curta e média duração é mais eficiente para motivar uma geração que cresceu contemporânea a existência da internet e que por vezes a frequenta com mais assiduidade do que ambientes de presença física.

- Independência: Este formato contribui para o desenvolvimento da independência do aluno na conquista do conhecimento necessário à sua formação, pois em geral o acesso à rede costuma ser individual.

- Flexibilidade: Dado que os vídeos ficam disponíveis na rede durante as 24 horas do dia, o aluno pode dedicar-se a eles no horário que lhe parece mais adequado. Além disso, tem a possibilidade de assisti-los tantas vezes quantas achar necessário e repetir trechos que não tenha compreendido, ao contrário do que acontece com o ambiente tradicional de sala de aula.

O formato proposto não é novidade: facilmente se acessam vídeos educacionais na rede mundial, cobrindo os mais diversos assuntos, entre eles EDO. Muitas instituições, inclusive, mantêm cursos disponíveis neste formato, USP e Unicamp, para citar algumas. Uma experiência relativamente nova e já consagrada trata-se da plataforma Coursera, que também disponibiliza diversos cursos à distância em formato de vídeo. A facilidade de acesso a estes cursos é brutal: os cursos são gratuitos e segundo matéria recente publicada no semanário CartaCapital [5], o Coursera oferecia, àquela época, 328 cursos gratuitos online através de 62 universidades de diversas partes do mundo, alcançando 2,9 milhões de usuários (dos quais cerca de 5\% são brasileiros) em 17 países. A plataforma edX, mais recente, tem proposta semelhante e contava então com 800 mil usuários (dos quais 23 mil são brasileiros).

Entretanto a experiência aqui descrita comporta algumas diferenças em relação àquilo que já está disponível na rede, em português. Em primeiro lugar, não se trata de uma aula tradicional de 50 minutos filmada, disponibilizando-a em seguida para que o aluno assista de novo aquilo que ele já assistiu antes. Ainda que esta dinâmica possa ser eficiente em muitos casos, a 
proposta aqui é disponibilizar um material de formato distinto (mas com conteúdo similar) ao que costuma ser apresentado numa aula tradicional.

Em primeiro lugar, os vídeos são de curta/média duração: no máximo 15 minutos. Este formato apresenta algumas vantagens do ponto de vista do aluno: ele pode focalizar o essencial daquele assunto através do vídeo; facilita a "revisita" àquele mesmo conteúdo quando necessário; não "cansa" tanto o usuário que tem por costume assistir coisas rápidas na internet. Do ponto de vista do professor, a dinâmica da aula filmada em vídeo facilita o uso de recursos audiovisuais como gráficos e animações que nem sempre são de simples incorporação à sala de aula tradicional.

\subsection{Os vídeos}

Foram disponibilizados no YouTube um conjunto de 23 vídeos com duração máxima de 15 minutos cada. Estes cobrem o conteúdo básico de um primeiro curso de equações diferenciais normalmente oferecido às turmas de engenharia: Equações de primeira (lineares, separáveis, exatas, quase exatas, soluções por substituição); equações de segunda ordem a coeficientes constantes; sistemas de equações lineares de primeira ordem; e soluções em série de potências. Os temas dividem-se em teoria, exemplos e aplicações, quando pertinente. A execução de cada vídeo foi feita seguindo as etapas:

- Montagem de uma apresentação de slides com o conteúdo da aula;

- filmagem da apresentação usando programa de captura de tela com gravação simultânea de narração para o conteúdo filmado;

- disponibilização do vídeo filmado no YouTube.

Ainda que a divisão dos vídeos em conteúdos sugira uma estrutura rígida para o curso, a total disponibilidade das aulas permite que esta estrutura seja quebrada. Alguns temas são recorrentes em diferentes aulas.

Como exemplo tome o modelo para queda livre considerando-se a resistência do ar:

$$
m \frac{d v}{d t}=m g-\kappa v^{p}
$$

onde $m$ é a massa do objeto em queda, $g$ é a aceleração da gravidade, $\kappa>0$ é a constante de arrasto, $p$ é uma potência racional positiva e $v=v(t)$ é a velocidade do corpo em queda.

O primeiro contato com este assunto ocorre no vídeo inaugural do curso "Introdução às Equações Diferenciais" para instigar a curiosidade do público a respeito das equações diferenciais. Usando as imagens do impressionante salto da estratosfera realizado pelo paraquedista Felix Baumgartner em 2012, uma das questões que surge naturalmente é sobre a velocidade máxima atingida neste salto, $1.173 \mathrm{kmh}^{-1}$, mostrada na figura 1.

A equação 1 expressa as forças agindo sobre o corpo em queda de acordo com a segunda lei de Newton. Há a força gravitacional contribuindo para a queda e uma força resistiva à queda que proporcional à (uma potência da) velocidade. É razoável o argumento de que quanto maior a velocidade, maior será a ação da força resisitiva. Entretanto, ele é insuficiente para garantir a existência de uma velocidade de queda limite para este corpo. Na vídeo-aula sobre campos de direções o assunto é retomado: é possível verificar graficamente o comportamento das supostas (porém ainda desconhecidas) soluções desta equação. Mas este argumento é computacional e o fato é que campos de direções não costumam ser muito convincentes para o aluno em início de curso. A terceira vídeo-aula, sobre equações autônomas, fornece outro argumento importante: 


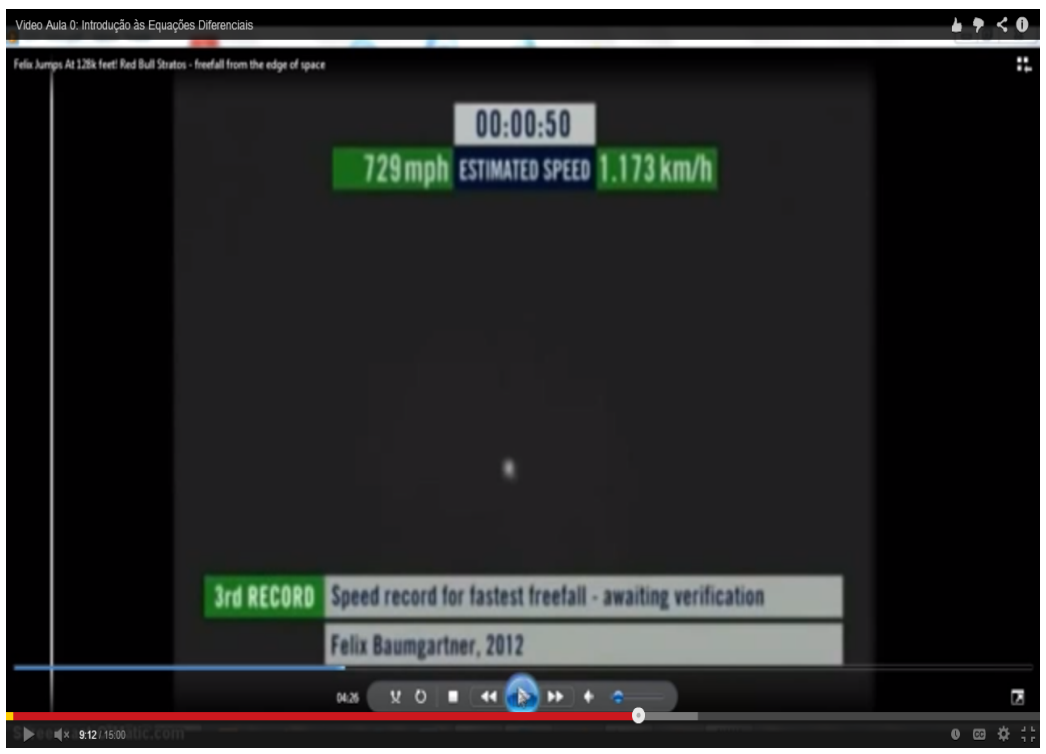

Figura 1: Vídeo exibindo a velocidade terminal atingida em salto da estratosfera.

$$
v(t)=V_{e s t}
$$

é uma solução estacionária, ou de equilíbrio, para a equação autônoma de primeira ordem,

$$
\frac{d v}{d t}=f(v)
$$

se e somente se $f\left(V_{\text {est }}\right)=0$. O esboço das soluções a partir do retrato de fase da equação 1 junto com o respectivo campo de direções, evidencia a existência de uma solução estacionária, isto é, a existência de uma velocidade terminal constante dada por:

$$
V_{e s t}=\left(\frac{m g}{\kappa}\right)^{1 / p}
$$

O uso destes recursos facilita a compreensão de fatos importantes como por exemplo a independência da velocidade terminal 4 em relação à velocidade inicial da queda, $v_{0}$. E o assunto ainda volta à tona em mais três vídeo-aulas: Equações lineares de primera ordem (caso $p=1)$; equações separáveis; e equações de Ricatti quando será possível comparar as estimativas qualitativas obtidas anteriormente com as soluções extas, cujo limite quando $t \rightarrow \infty$ é exatamente $V_{\text {est }}$ dada pela equação 4 .

Fecha-se aqui um ciclo de aprendizado que representa a síntese da matemática aplicada: uma situação real, seu modelo modelagem matemático, visualização numérico-computacional e a obtenção e validação de solução analítica. Convém salientar que estas mesmas etapas podem ser percorridas também em sala de aula, mas a dinâmica é muito diferente, pois a alternância entre as mídias, quadro, projetor e internet, pode ser lenta e acidentada quebrando assim o fluência natural da aula.

\subsection{Atividade Proposta: Oscilações Harmônicas}

Oscilações mecânicas (sistema massa-mola, pêndulo linear) e elétricas (circuito RLC) são exemplos de equações de segunda ordem a coeficientes constantes como:

$$
a y^{\prime \prime}+b y^{\prime}+c y=f(t)
$$


onde os coeficientes $a \neq 0, b$ e $c$ são reais. A variável $y$ é a posição da massa no instante $t$ no caso mecânico, e a carga $q$ no circuito no caso elétrico. Tanto para oscilações mecânicas como para elétricas, o termo resistivo ao movimento é aquele associado à derivada primeira. No primeiro caso tem-se um coeficiente de atrito dependente do meio e no segundo tem-se a resistência do resistor no circuito.

Como parte da avaliação, foi proposto aos alunos a construção de um oscilador harmônico físico ou virtual e, posteriormente, a apresentação do modelo em sala de aula. Os projetos eram diversos: circuitos RLC montadas em placas proto-board ligadas a um osciloscópio (figura 2), circuitos RLC montados em programas simuladores de circuitos (multisim ou pspice por exemplo), sistema massa-mola físco, sistema-massa mola virtual (desenhado no SolidWorks ou no Matlab) e pêndulos lineares físicos. Estes projetos deveriam contemplar os casos:

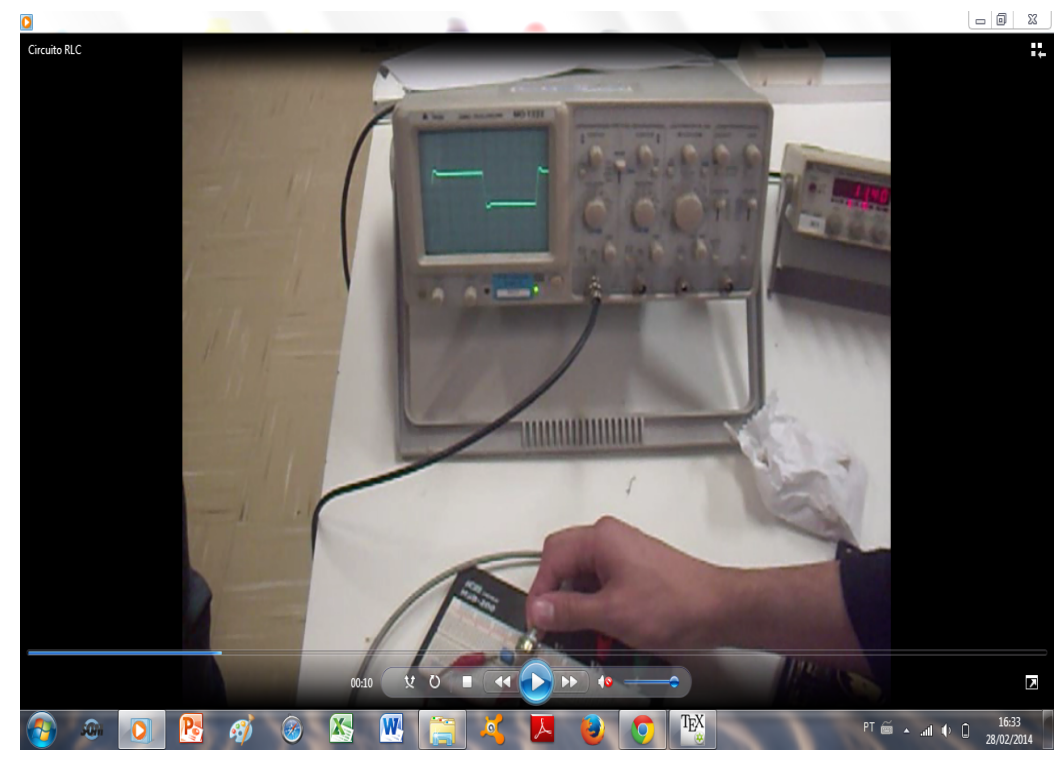

Figura 2: Vídeo de aluno exibindo circuito RLC físico.

- Oscilação livre sem amortecimento;

- Oscilação livre com amortecimento subcrítico;

- Oscilação livre com amortecimento supercrítico; e

- Oscilação forçada.

Para aqueles modelos cujos casos não são realizáveis, uma explicação física razoável era cobrada. Por exemplo, o circuito RLC montado em placa com componentes não contempla o primeiro caso de oscilação livre uma vez que é impossível eliminar totalmente a resistência no circuito (mesmo sem o resistor!), já que a fiação e o osciloscópio possuem resistências internas que não se podem eliminar. E assim, percebe-se como o modelo matemático para a situação física real pode encerrar certas limitações.

Ao longo dos semestres a forma de apresentação deste trabalho sofreu algumas alterações, iniciando com apresentações abertas em sala, até culminar com a filmagem em vídeo e postagem no YouTube destes experimentos, nos mesmos moldes das vídeos-aulas que os alunos vinham assisitindo. Notou-se um maior envolvimento dos alunos com este formato, agindo com maior responsabilidade (por se tratar de um vídeo público, uam vez que a "entrega" do trabalho se realiza através de postagem). 


\section{Resultados}

Foi aberto um canal no YouTube com as vídeo-aulas que conta atualmente com 70 inscritos, dos quais uma boa parte não é de alunos das turmas presenciais, ou seja, a postagem de vídeo-aulas neste canal ajuda a democratizar o acesso à informação. Até o final de fevereiro de 2014, os vídeos disponíveis no canal contabilizavam 12.591 visualizações, acima de 500 visualizações por módulo na média, o que mostra que o alcance deste recurso ocorre numa escala assusatadoramente superior ao da sala de aula.

Este resultado pode ser considerado como um efeito colateral positivo, já que o objetivo primeiro do projeto era atingir apenas os alunos que frequentassem as aulas presenciais. Este efeito sugere que o projeto possa ser ampliado e aperfeiçoado tendo em vista esta característica que não havia sido notada anteriormente.

Do ponto de vista dos alunos que usam as vídeo-aulas como material de apoio complementar, fizemos uma rápida enquete de opinião com a turma que utilizou o recurso, para tentar entender melhor como o recurso foi recebido pelo corpo discente. Esta pesquisa constava de cinco perguntas com resposta de múltipla escolha. Um pouco menos da metade dos alunos topou particpar (39 alunos em duas turmas de 45) e os resultados desta enquete encontram-se sintetizados na tabela 1.

\section{Conclusões}

Não se trata de dizer que o uso destas vídeo-aulas revoluciona o processo de ensino ou de aprendizagem, pois o aluno pode continuar tendo a mesma atitude passiva diante delas que tem diante da aulas presenciais. O que pretendemos é que o uso das aulas em vídeo estimule a independência do aluno e o ajude à medida que flexibiliza os seus horários de estudo.

Mas o ponto central que atacamos com estas vídeo-aulas é a motivação do aluno. Procuramos uma mídia que se aproxime do seu dia-a-dia e que seja (dentro da medida do possível) atraente. Este caminho estimula a exercitar uma maior independência na conquista do conhecimento, ainda que a atenção às aulas presenciais seja evidente, como se percebe pelo altos índices obtidos nas respostas das perguntas 1 e 5 (tabela 1) da seção anterior. Isso mostra que o uso do recurso de vídeo para o aluno é auxiliar, e que o professor ainda é indispensável.

Quantos aos resultados obtidos para as outras perguntas, particularmente a terceira mostra um acerto na escolha do tempo de duração dos vídeos e na adequação do balanço entre teoria e exemplos. Os resultados obtidos para a quarta pergunta nos estimulam a aperfeiçoar a ferramenta não só do ponto de vista técnico como também de conteúdo.

Claro que os vídeos (e tampouco as aulas) não suprimem o aprofundamento na bibliografia específica e realização de exercícios, este comprometimento por parte do aluno continua sendo fundamental para seu aprendizado. Não há segredo, matemática se aprende fazendo, experimentando, cometendo erros e aprendendo com eles, se propondo novas questões e desafios, como sugere [2]. Esperamos entretanto, que o uso desta ferramenta abra a possibilidade de se pensar a sala de aula como um espaço que pode ser aproveitado de uma maneira mais integrada entre educadores e educandos, como instante/espaço de discussão de dúvidas e ideias. Uma vez que o conteúdo do curso pode ser exposto em um pouco menos de 6 horas de vídeo (enquanto que nas aulas presenciais isso demora muito mais: 72 horas) a sala de aula pode ser repensada. Isso será possível desde que haja um comprometimento de ambas as partes em utilizar os recursos extra-sala de maneira efetiva e responsável. 


\begin{tabular}{|c|c|c|}
\hline $\begin{array}{l}1 \text { - Com relação às vídeo-aulas de MA70G, assinale a(s) alternativa(s) } \\
\text { que mais se aproxima }(\mathrm{m}) \text { da sua opinião a respeito }\end{array}$ & Qtdade. & $\%$ \\
\hline Elas não me ajudaram em coisa alguma & 0 & 0,0 \\
\hline Elas me ajudaram a fazer as provas & 17 & 48,57 \\
\hline Elas me ajudaram a entender as aulas presenciais & 27 & 77,14 \\
\hline Elas me ajudaram a entender o livro texto & 9 & 25,71 \\
\hline $\begin{array}{l}2 \text { - Com relação ao conteúdo das vídeo-aulas de MA70G, assinale a } \\
\text { alternativa que mais se aproxima da sua opinião a respeito }\end{array}$ & Qtdade. & $\%$ \\
\hline Pouca teoria e poucos exemplos (resumido demais) & 2 & 8,0 \\
\hline Excesso de teoria e poucos exemplos & 4 & 10,26 \\
\hline Excesso de exemplos e pouca teoria & 1 & 2,56 \\
\hline Um balanço adequado entre teoria e exemplos & 34 & 87,18 \\
\hline Muita teoria e muitos exemplos (extenso demais) & 0 & 0,0 \\
\hline $\begin{array}{l}3 \text { - Com relação ao tempo de duração das vídeo-aulas de MA70G, assinale a } \\
\text { alternativa que mais se aproxima da sua opinião a respeito }\end{array}$ & Qtdade. & $\%$ \\
\hline Os vídeos são muito curtos & 1 & 2,56 \\
\hline Os vídeos tem tempo de duração adequado & 35 & 89,74 \\
\hline Os vídeos são muito compridos & 3 & 7,69 \\
\hline $\begin{array}{l}4 \text { - Com relação à qualidade das vídeo-aulas de MA70G, assinale a } \\
\text { alternativa que mais se aproxima da sua opinião a respeito }\end{array}$ & Qtdade. & $\%$ \\
\hline A qualidade gráfica e sonora deixa a desejar & 0 & 0,0 \\
\hline A qualidade gráfica é boa mas a sonora deixa a desejar & 9 & 25,0 \\
\hline A qualidade gráfica deixa a desejar mas a sonora é boa & 3 & 8,33 \\
\hline Tem boa qualidade gráfica e sonora & 24 & 66,67 \\
\hline 5 - De forma geral eu & Qtdade. & $\%$ \\
\hline $\begin{array}{l}\text { Não gostei da experiência de utilizar vídeo-aulas como recurso } \\
\text { de aprendizado, prefiro assistir apenas aulas em sala }\end{array}$ & 0 & 0,0 \\
\hline $\begin{array}{l}\text { Sou indiferente à utilização vídeo-aulas como recurso de } \\
\text { aprendizado }\end{array}$ & 1 & 2,56 \\
\hline $\begin{array}{l}\text { Gostei da experiência de utilizar vídeo-aulas como recurso adicional } \\
\text { de aprendizado, mas não dispenso assistir aulas presenciais em sala }\end{array}$ & 30 & 76,92 \\
\hline $\begin{array}{l}\text { Gostei da experiência de utilizar vídeo-aulas como recurso adicional de } \\
\text { aprendizado e acho que o recurso dispensa assistir aulas presenciais em sala }\end{array}$ & 8 & 20,51 \\
\hline
\end{tabular}

Tabela 1: Resultados da Enquete de Opinião a respeito das vídeo-aulas

\section{Referências}

[1] L. H. Bezerra et al., "Introdução à Matemática", EDUFSC, Florianópolis, 1995.

[2] E. B. Burger, M. Starbird, "The 5 Elements of Effective Thinking", Princeton University Press, Princeton, 2012.

[3] K. Devlin, "Introduction to Mathematical Thinking", Keith Devlin, Palo Alto, 2012.

[4] A. Lopes, Algumas reflexões sobre a questão do alto índice de reprovação nos curos de Cálculo da UFRGS Matemática Universitária, 26/27 (junho/dezembro 1999) 123-146.

[5] T. Oliveira, A Nova Fase do Ensino Online, em Suplemento Tecnologia e Inovação, Carta Capital, no. 745. (Ano XVIII). 